\title{
Applying Haptic Systems in Serious Games: A Game for Adult's Oral Hygiene Education
}

\author{
Herbet F. Rodrigues, Liliane S. Machado \\ Laboratory of Technologies for Virtual Teaching and \\ Statistics (LabTEVE) \\ Federal University of Paraíba \\ João Pessoa/PB - Brazil \\ herbetferreira@gmail.com, liliane@di.ufpb.br
}

\author{
Ana Maria G. Valença \\ Department of Clinics and Social Odontology \\ Center of Health Sciences \\ Federal University of Paraíba \\ João Pessoa/PB - Brazil \\ anamvalenca@gmail.com
}

\begin{abstract}
Most commonly used in virtual reality systems, haptic devices are taken as an important way of providing greater interaction and engagement between the user and the computer system, particularly in problems that depend on skill and use the sense of touch. It is known that the development of serious games, composed by immersive environments and unconventional devices can contribute with the motivation and learning of the players. However, an important question relates to how to integrate these devices to conform its limitations to a specific problem addressed in serious game. In the present work it is presented a study related to the integration of haptic systems for serious games for adult oral hygiene in order to adjust teaching content to computational resources. Thus, a specific process model to the development of serious games was applied to the creation of TouchBrush serious game, dedicated to education of good tooth brushing practices.
\end{abstract}

Keywords- Haptic Systems, Serious Games, Games for Dentistry, Game Development Process

\section{INTRODUCTION}

Virtual Reality (VR) is applied in a quite diverse way in knowledge areas such as Medicine, Engineering and Education. New applications are constantly emerging due to requests from the market and technological researches. There are several goals for which VR applications are developed, such as education, entertainment and training.

For teaching, more than vision and hearing are necessary for the full perception of the physical phenomena, it is difficult for a teacher, for example, to explain the tactile and strength perception of an object without students experiment it in some way and investigate characteristics of its stiffness, tenderness, texture and shape. This tactile exploration is done through tactile and kinesthetic sensory systems, which correspond to the spatial and temporal distribution of the forces on the hand of the user (Basdogan et al., 2000) in systems known as haptic systems.

The haptic systems can provide user tactile feedbacks in form of vibrations and forces. The intention is to provide the ability to touch and feel objects present in a virtual environment, providing a greater sense of realism in the environment where the user is immersed (Burdea, 1996). This perception is important to allow the user to understand and navigate in virtual environments in a more natural and intuitive way (Faust \& Yong-Ho, 2006).

Concurrently with the development of VR applications for education, the society has experienced a particular category of games in order to extrapolate the idea of entertainment and offer experiences geared to the learning and training. These games, known as serious games, mainly target the simulation of common situations of everyday life in order to provide training for professionals, create critical scenarios in companies, educate children, youth and adults, as well as stimulate imagination and comprehension of certain social dynamics and natural phenomena (Blackman, 2005) (Moraes et al., 2012).

Serious games are used in various sectors, such as military, education, business, government, political, religious and artistic (Rankin \& Vargas, 2008) (Barnes et al., 2009), among others. The serious games are also an important ally of education, training and simulation for health (Marsh, 2011). By their use, difficulties in obtaining materials, product validation and staff training can be minimized. They can also be useful to rehabilitation and teaching of healthy habits, favoring professionals and patients (Moraes et al., 2012). In this sense, studies show that the use of serious games with immersion in VR environments are able to relieve stress, reduce pain and assist in psychomotor rehabilitation processes, but also confirm that the acquired knowledge is transferred to real environments when games and applications are used for education and training reasons (Johnsen et al., 2007) (Guillén-Nieto \& Aleson-Carbonell, 2012).

The incorporation of haptic systems in performing the activities of tactile nature in serious games allows to widen the level of realism and to reach a more efficient way of involvement. Its use can result in higher levels of knowledge absorption by the player. However, it is known that haptic systems have limitations and each device has different characteristics as its shape, strength return capacity and manipulation space, among others (Burdea \& Coiffet, 2003).

So, this work addresses the use of haptic systems in serious games for health education, specifically in the Dentistry area 
and oral adult hygiene. It recognizes the need to adapt the type of device to the problem addressed and vice-verse, integrating content and device without compromise the content itself. In this context, was applied a specific model process for serious games in the development of the game TouchBrush.

\section{Serious Games Development}

The games area has been through several modifications since its origins until the present day, and its development processes accompanied these changes. In the past, games were created by small teams, consisting mainly of programmers and were soon completed. However, this reality contrasts with nowadays for the need of diversified content (Schell, 2008). Thus, the current games development follows distinct patterns. It is necessary to deal with heterogeneous teams and, in some circumstances, with long-term projects.

The stimulation of cognitive functions, motivation and knowledge acquisition are fundamental elements of the conception of serious games (Machado et al., 2009). The specific purpose of these applications demands planning and support of experts of the specific content area. In Figure 1 is possible to observe the elements of serious games to be added in the development of regular games. It is also possible to see that the experts team need to work together with other project teams. It is required mainly by the content complexity and, specifically by the pedagogical aspects present in the serious games.

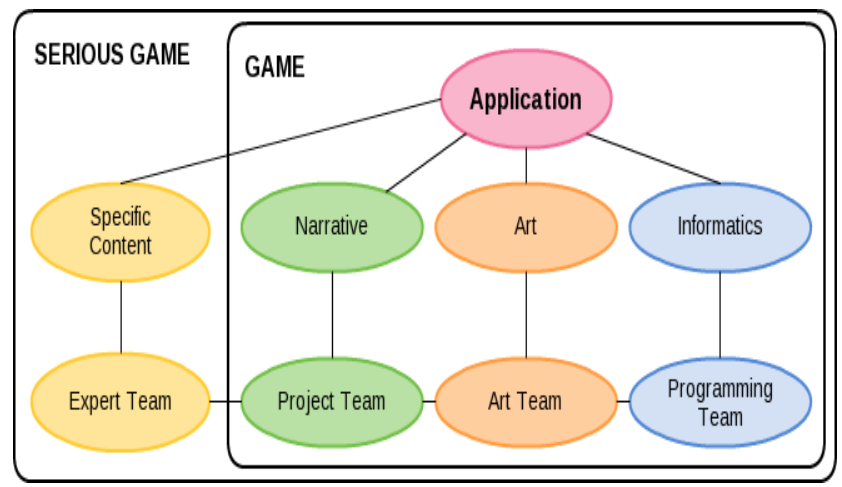

Fig. 1. Structure of the Serious Game Unified Process (SGUP).

Among many software development models designed in recent years, some have been adapted to create specific models for games. However, these are usually superficial and do not always fit the needs of games that include specific content approaches, as it is in the case of serious games for teaching. Some of these initiatives are the Game Waterfall Process (GWP), the Extreme Game Development (XGD) and the Game Unified Process (GUP) (Flood, 2003) (Demachy, 2003). Such models do not possess the same characteristics, mechanisms and specialized people to deal with and manage the specific content of serious games, as well as some do not worry about the quality of the content from the initial stages of the development process.
The development of the Touchbrush game used the process model proposed by Rodrigues (2011) for the development of the serious games, called Serious Games Unified Process (SGUP). This model was inspired by the essence of Rational Unified Process (RUP) and is based on the management of both computational concepts related to games and their specific content, promoting the integration between different areas aiming at a game with content closer to reality. Thus, to include the characteristics, roles and activities for the serious games development, noting the need to treat specific aspects of content two subjects, the SGUP includes in the model: Specific Content Project Management and the Game Bible Management. Table I presents a description of how these new disciplines are present in the development model.

table i. AdDitional subjects of the SGUP.

\begin{tabular}{|c|c|c|}
\hline Subject & Description & Main functions \\
\hline $\begin{array}{l}\text { Specific } \\
\text { Content } \\
\text { Project } \\
\text { Management }\end{array}$ & $\begin{array}{l}\text { Specific Content Project } \\
\text { Management is } \\
\text { concerned to meet the } \\
\text { specific needs of the } \\
\text { serious game content } \\
\text { with the help of experts } \\
\text { in the area that the game } \\
\text { applies. }\end{array}$ & $\begin{array}{l}\text { - Professional } \\
\text { expert in } \\
\text { content area; } \\
\text { - Potential } \\
\text { User. }\end{array}$ \\
\hline $\begin{array}{l}\text { Game Bible } \\
\text { Management }\end{array}$ & $\begin{array}{l}\text { The Game Bible } \\
\text { Management is } \\
\text { concerned to to meet the } \\
\text { entertainment needs of } \\
\text { identifying and } \\
\text { specifying the features } \\
\text { that will be present in the } \\
\text { serious game as script, } \\
\text { gameplay, concept art, } \\
\text { challenges, among } \\
\text { others. }\end{array}$ & $\begin{array}{l}\text { - Game } \\
\text { Designer; } \\
\text { - Artist. }\end{array}$ \\
\hline
\end{tabular}

Just as in a Rational Unified Process (RUP), the SGUP consists on two dimensions: static (vertical) and dynamic (horizontal). The static structure consists on a set of subjects taken over time. Each one is defined in terms of who (roles), how (activity), what (artifact) and when (activities flow). Other definitions of the model's roles, activities, artifacts, and activities flow are similar to the RUP's. The dynamic structure consists on structuring how the set of subjects of the static structure behaves along the timeline.

The SGUP has a set of four phases (Design, PreProduction, Production and Post-Production), ten subjects divided into seven breeding (Requirements Analysis, Specific Content Design, Game Bible, Technical Design, Implementation, Test and Distribution) and three supporting disciplines (Configuration and Change Management, Project Management and Environment). Figure 2, also known as "whale graph", displays how these subjects behave in the SGUP dynamic structure phases, or effort employed along each phase. The Specific Content design phase is were is established the content concepts of the serious game, and organizing them 
into computational requirements. In this phase is described and justified the serious game, keeping in view the didactic or pedagogical needs of content that will be informed by professionals of the area. These needs must be mediated by other team members, depending on their adaptation to the computational resources available.

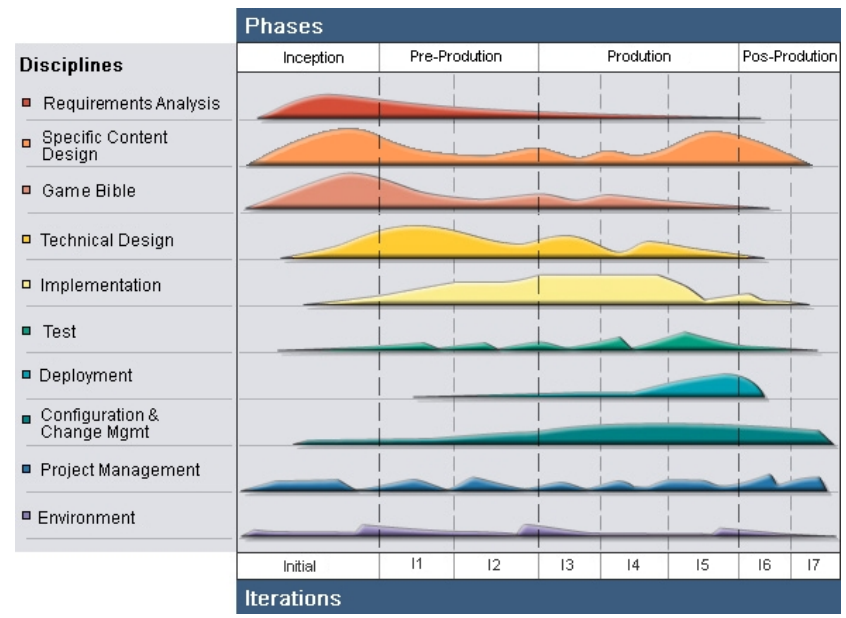

Fig. 2. Structure of the Serious Game Unified Process (SGUP).

\section{The Touchbrush Game}

Although serious games aimed at Dental issues are important tools of educational intervention, little is known about their availability and their characteristics in the literature. A survey and evaluation of the serious games existent in the literature, and in the game market related to the type of message and pedagogical aspect presented, target audience, interaction devices, game distribution and display type, found out that the games are aimed at children and addressing basic concepts about nutrition and oral hygiene. As examples, there are the Dental Space Odyssey, Dr. Dentist Game, Tooth Brush Patch, Dental Damage, Whack a Molar, Dental Distress, Dentist Brushing Teeth and Brush your Teeth.

The main platform adopted by these games is Adobe Flash, characterized by easy development and compatibility with most operational systems (Windows, Linux, Android, IOS, etc.). Other games stood out for having a script for a diverse audience, with a wider range of challenges and detailed view. In this context, we can cite the Glenn Martin, DDS: Dental Adventure, an online game developed with the company Nickelodeon. In this serious game, the player becomes a dentist and travels through eight different cities of the United States to solve oral health problems in patients.

Among the games found that have their design with a little more educational content, several are devoted to the acquisition of hand dexterity or advanced concepts and the target public are students or professionals in the field of Dentistry. An example is the Break Away, developed in partnership with the Medical College of Georgia in the United States, Virtual Dental Implant Training (VDIT) (Break Away, 2009). The VDIT is based on a serious game for the simulation of procedures in dental implants.
The Dentist Brushing Teeth and Brush your Teeth are examples of games developed for the Android platform to run on smartphones and tablets. The interaction with these games is restricted to the display (they do not support 3D interaction).

Another serious game found on literature, this time aimed at children, was developed by the Department of Computer Science and Information Engineering from Taiwan National University (Chang et al., 2008). The game, called Playful Toothbrush, aims to help parents and teachers in the motivation of children from kindergarten to learn proper and thorough cleaning of the teeth. Their game design is based on the principles of occupational therapy, leading the kids to see the activity of oral hygiene as an enjoyable and interactive play. With this, children's knowledge about teeth brushing and healthier habits will increase.

An analysis of the characteristics present in most of the games dedicated to inform about correct ways to brush the teeth showed that children are the target audience and that the games offer the same form of interaction, visualization and plot. These games were grouped as "Children's games" in Table II. Additionally, it was observed that most games display the type of view 2D, and those with $3 \mathrm{D}$ display are dedicated to professional education, as the VDIT game.

TABLE II. Characteristics of SERIOUS games Related to DENTISTRY FOUND IN THE LITERATURE.

\begin{tabular}{l}
\hline Game \\
\hline Children's games \\
Message: Basic concepts of nutrition and oral \\
health \\
Target Audience: children \\
Interaction: mouse + keyboard + touchpad/display \\
(tablets or smart phones) \\
Distribution: Free and available in Web \\
Visualization: 2D \\
Dental Adventure \\
Message: Several concepts and treatments in oral \\
health \\
Target Audience: Children (who can read) and \\
adults \\
Interaction: mouse + keyboard \\
Distribution: Free and available in Web \\
Visualization: 2D \\
Toothbrush \\
Message: Techniques for children's oral hygiene \\
Target Audience: Children from kindergarten \\
Interaction: Real teeth brush with a tracking device \\
Distribution: Off the shelf commercial \\
Visualization: 2D \\
\hline Playful
\end{tabular}

The games about oral health have predominantly children as target audience, mainly offering as thematic and pedagogical content basic concepts of oral health. With that, the content is limited to the diversification of the concepts in dentistry, and can not delve into many subjects. The opposite can be seen in the game Dental Adventure, which has as its target audience 
children and adults and incorporates diverse knowledge about oral health from diseases, to care and treatment forms. It is important to highlight that the authors evaluated the Playful Toothbrush game and found that the incorporation of a different device used in the game, increased the usability level and offered a more motivating way when the children performed the activities. With this, the possibilities of incorporating a non conventional device in games expands the creation of new themes that provide a new type of interaction, bringing new audiences with interest to play and learn about issues related to Dentistry.

As an example of games that use haptic devices, the HaptiCast can be highlighted (Andrews et al., 2006), with 3D visualization, which puts players in a first-person environment. It was designed to provide action and interactivity using the PHANToM Omni haptic device. Another example is the Haptic Battle Pong (Morris et al., 2004), a version of the Pong game with haptic device support. In it, the force return provided by the device is used to show the contact between the ball and the player's racket. However, the haptic effects presented are limited, not showing all the potential that the haptic device can provide. From Paolis et al. (2007), a pool game was developed using the PHANToM Omni haptic device, in order to make the game as interactive and realistic for the user as possible. With the device, it is possible to feel the contact between the bat and ball at the hit.

The TouchBrush Game has been proposed as a tool for learning about good oral hygiene practices for adults. Its proposal includes the union between knowledge, fun and motor skill for the development of a serious game. Using the development model process SGUP, it was aimed to promote the integration between different areas of knowledge in order to achieve a good set of approach, content and technology. Thus, from the observation of previous serious games with oral health theme, the TouchBrush development intended to understand the integration challenges of a haptic device to a serious game for adults.

\section{A. Requirements}

The areas of knowledge present in this multidisciplinary team work integrated professional experts in Computing, Dentistry and Statistics in order to follow all SGUP steps. During the model application, the professionals have played more of a role in the execution of some of the process activities, such as the Implementation discipline, in which the Computer professional played roles such as designer, audio engineer and developer. Other roles, as Project Manager, were held together by various professionals.

For the activities of the Requirements Analysis discipline, two factors were primarily defined: the target audience and the purpose. Only with these two specified points was possible to proceed with the next activities of the Conception phase of the game. In this sense, it was defined as the target audience the adults and the objective to inform and encourage the learning of concepts and techniques related to oral hygiene. To apply this knowledge, it was first necessary to know the most common brushing techniques existent and the most indicated for adults. This allowed, in the discipline of Specific Content
Design, to be possible to define which technique would be used in the game and how it should be transmitted to the player.

During the activities of the discipline Specific Content Design, meetings were held with the multidisciplinary team to define the various aspects of the game, including: the challenges and tasks within the oral hygiene theme and the research on the acceptance of potential users regarding the facility of use of a haptic device. Two objectives were defined for this research: the user's ability to feel the material properties of the virtual objects present in the game and the possibility to perform the correct movements with the device following the correct brushing technique.

The Bass Technique (Lindhe et al., 2003) of brushing was pointed out by experts to be used in game tasks, teaching about how to clean the teeth and prevent gum inflammation. To apply the technique, they defined five main movements to be performed by users:

- brush outer surface of posterior teeth (buccal surface)

- brush inner surface of posterior teeth (lingual surface)

- brush biting surface of posterior teeth (occlusal surface)

- brush outer surface of anterior teeth (facial surface)

- brush inner surface of anterior teeth (lingual surface)

For the haptic 3D interaction, several devices were considered according to their price, degrees of freedom (DOF), handling and platform support. The PHANToM Omni was the device that presented the best cost-benefit. The device has one of the lowest prices among the 3DOF devices, is supported by the most popular platforms and presents a handling very similar to a toothbrush. The device is composed by an articulated robotic arm, with a stylus in the end, attached to a base. The joints of the robotic arm allow translations and rotations of a reference point in three dimensions. Servomotors provide force feedback up to $3.3 \mathrm{~N}$ only to translational movements in a $160 X 120 X 70 \mathrm{~mm}$ workspace. The handling of the stylus in the PHANToM Omni can be easily changed to simulate the toothbrush and three-dimensional movements.

Preliminary tests with the device showed difficulties in manipulating it for movements from back to front, as when someone is brushing their own teeth. In this case, the structure of the device does not allow the positioning of the stylus with the point directed to the user since the workspace is limited (Figure 3a). A possible solution would be the use of the device in an reverse position, with the base in front of the stylus (Figure 3b) in an uncomfortable position. Additionally, the use of the stylus could not be reversed because of the actuator of force positioned in the coupled end (Figure 3c). Those observations convinced the development team to adopt a third person approach, with users brushing someone's teeth (Figure 3d).

\section{B. Tests with users}

A research with potential users was critical to evaluate how tasks would be presented in the game. It was important to understand how the activities would be performed, which of 
them should be remodeled and how they could be properly ordered for Specific Content Design of SGUP according to the haptic device limitations. Besides, it is known that most users have never used a haptic device before and the tests also were intended to understand the difficulty experienced by users performing movements with the device. This research was approved by an Research Ethic Committee.

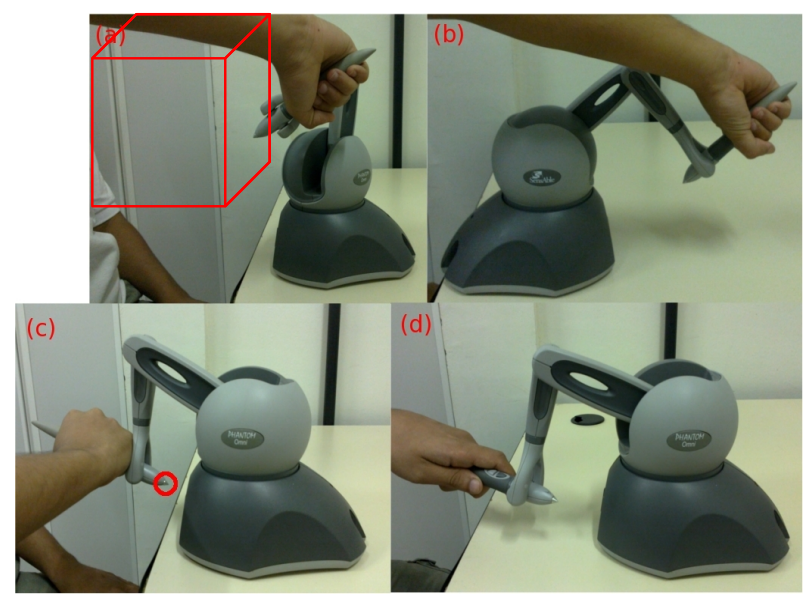

Fig. 3. Observations about the manipulation of the device when handling it as a toothbrush: a) limitation of workspace; b) device in reverse position; c) inversion of handling; d) handling for a third person approach.

Two applications were developed for the tests and used the CyberMed framework (Machado et al., 2009). The first one included a side by side pair of spheres with different material properties but visually identical. The left sphere was configured as a gums with properties of soft deformation and medium friction, and the right sphere was configured with hardness and low friction, as the teeth. These properties were attributed by an expert who calibrated the models previously. This application was used in the first testing phase to evaluate the ability of the user to feel the material properties of two distinct spheres in the virtual environment.

The second application was developed as a prototype of the game, without any details regarding the script, scenarios and texts, among others, and contained a 3D virtual model of the gum and teeth, and a 3D virtual model representing the toothbrush (Figures 4 and 5). The latter could be guided by the user through the haptic device. This application was used in the second testing phase to check users ability to perform the correct brushing movements with the haptic device.

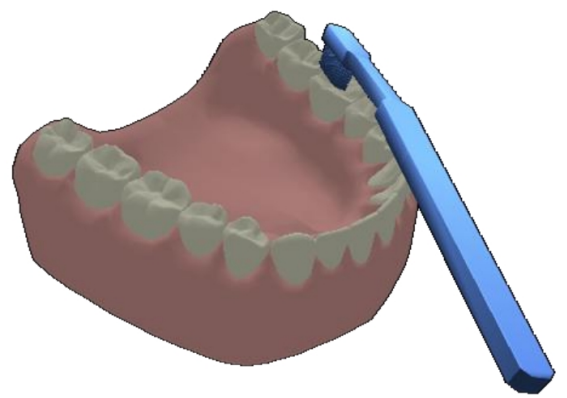

Fig. 4. Models in game prototype: gum, teeth and toothbrush.

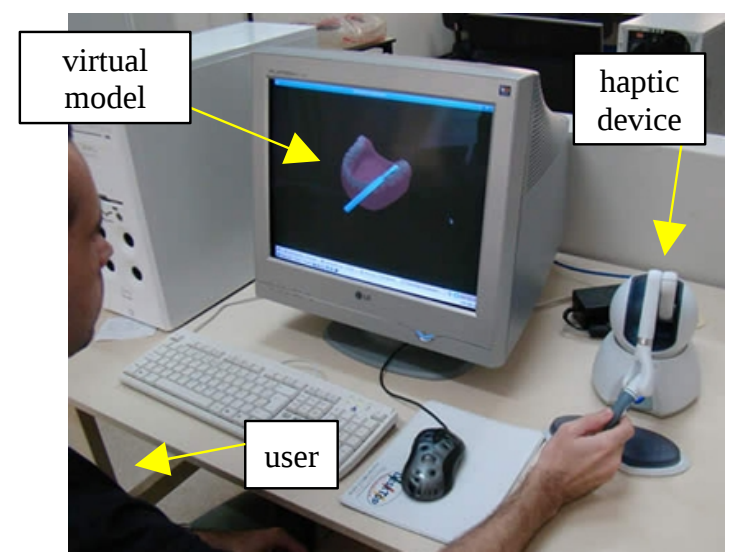

Fig. 5. User interacting with the game prototype.

The tests with the applications were performed in the Laboratory of Technologies for Virtual Teaching and Statistics (LabTEVE - http://www.de.ufpb.br/ labteve) and evaluated the opinion of 25 adults (18 years old or above). For that, a form composed by 15 multiple choice questions was prepared with an expert used to teach the theme to potential users of the serious game in a daily clinical practice. The final form was approved by the expert that checked the content and clearness of the questions. The questions were grouped in five categories:

1. the feeling about material properties;

2. the facility to performing the five main brushing movements with the device;

3. the comfort using the haptic device;

4. the ability with computers;

5. general information of user (age, sex and schooling).

The adults initially experienced the material properties of the spheres touching each individually and exploring its features through the haptic device. After this interaction, the interviewer read the form questions about what the user "noticed" or "felt" in each of the spheres, and ticked user's answer.

In the second stage of the tests, the users tried to perform the brushing movements according to the technique. The questions relating to this stage were completed by the interviewer according to how they evaluated at the time the user performed the movements. In other words, the interviewer recorded if the user easily performed the movement, performed with difficulty or was unable to perform the defined movement. At this point is important to mention that the same interviewer was present in all the tests. It is noteworthy that to perform the movement with ease, the user does not necessarily have to rotate the brush at a $45^{\circ}$ angle and make vibratory movements, but, do sweeping movements from the teeth's root until its tip. After completing all tasks, were formulated the last three groups of questions. 
The results showed that the users easily used the haptic device, and 98\% were able to perform all brushing movements, some more easily and others not so easy. The tests on the material properties (with the two spheres) showed that $96 \%$ of the users could feel the difference between the sphere on the left with the sphere on the right. Among them: 36\% indicated they felt clearly this difference and $60 \%$ indicated they felt difference, but a very subtle one.

Referring to the second stage of testing, the interviewer reviewed the brushing movements performed by users. With $100 \%$ of achievement, the easier movement was to brush the lateral teeth on the face chewing. Regarding the other brushing movements, putting them in order from easiest to hardest, the result was: front teeth (outer face), lateral teeth (outer face) and lateral teeth (inner face). It is important to highlight that among users who were able to move the brush with the haptic device and perform the movements correctly there are users who already have experience with the use of computers (84\%) and also users who have never had previously contact with a computer (16\%). These data suggest that the haptic device chosen is an easy instrument, with good usability and can be used by anyone, regardless of their knowledge and computer skills. Figure 2 illustrates a user performing the second step of the tests and interacting with the game prototype using the haptic device.

In the questions regarding the haptic device use, $68 \%$ of the users responded that they felt quite comfortable with the device. The remaining 32\% said they felt little comfortable. However, 84\% reported it is an easy to use device, and only $8 \%$ thought it is difficult to use. It is also important to note at this stage that, among individuals who had more facility with the device, there were people with no schooling (illiterate) and among those who have had difficulties; there were people with high level of education (graduated). These data suggest that the facility to use the device is not associated with the level of educational knowledge, but, to the experience with other types of tools and equipment.

\section{Content definition}

The connection to a support base and limited space of movement of the haptic device needed to be observed in the context of the activities to be performed in the game.

From the results obtained in the tests with the game prototype, the tasks and difficulty levels were set up. Thus, among the tasks performed by the users, it was suggested that the game would have three increasing difficulty levels, each following the movements that were performed easier until those executed with greater difficulty. Table III presents the tasks and levels defined.

Finalized the main activities for the definition of the specific content of the serious game, the activities of the discipline of Game Bible Management began, in which it was defined in depth the most important elements inserted in the game, like the script, the concept art (game design), the game play, mechanics and in game and out game interfaces.

In serious games, the Game Bible is used to guide the entire process of game development, containing its specifications and also the history of its conceptual evolution. Just as electronic games and entertainment, no development or implementation must be started until this specification is completely ready (Moraes et al., 2012).

TABLE III. LeVels ANd TASKS SET For the game.

\begin{tabular}{|c|c|}
\hline Levels & Tasks \\
\hline Level 1 & $\begin{array}{l}\text { In a total of } 5 \text { tasks, brush: } \\
\text { - } \quad \text { The whole tooth; } \\
\text { - } \quad \text { The biting face (occlusal surface); } \\
\text { - } \quad \text { Front face; } \\
\text { - } \quad \text { Right side of the tooth; } \\
\text { - } \quad \text { Left side of the tooth. }\end{array}$ \\
\hline Level 2 & $\begin{array}{l}\text { In a total of } 4 \text { tasks, brush: } \\
\text { - Lower teeth (right and left) in the biting surface } \\
\text { (occlusal surface); } \\
\text { (occlusal surface). }\end{array}$ \\
\hline Level 3 & $\begin{array}{l}\text { In a total of } 3 \text { tasks, brush: } \\
\text { - Front teeth on the outer face (lingual surface); } \\
\text { - Lateral teeth (right and left) on the outside (buccal } \\
\text { surface). }\end{array}$ \\
\hline
\end{tabular}

\section{IMPLEMENTATION}

The high-level architecture of the game, with the main modules, is illustrated in Figure 6. The central layer, called Framework, has the modules Chart, Physical and Haptic, which contain all classes needed for startup graphic scene, haptic device initialization, generation of objects and their physical characteristics, but also, the control positions, collisions and forces which are used by the Game Logic layer (top layer).

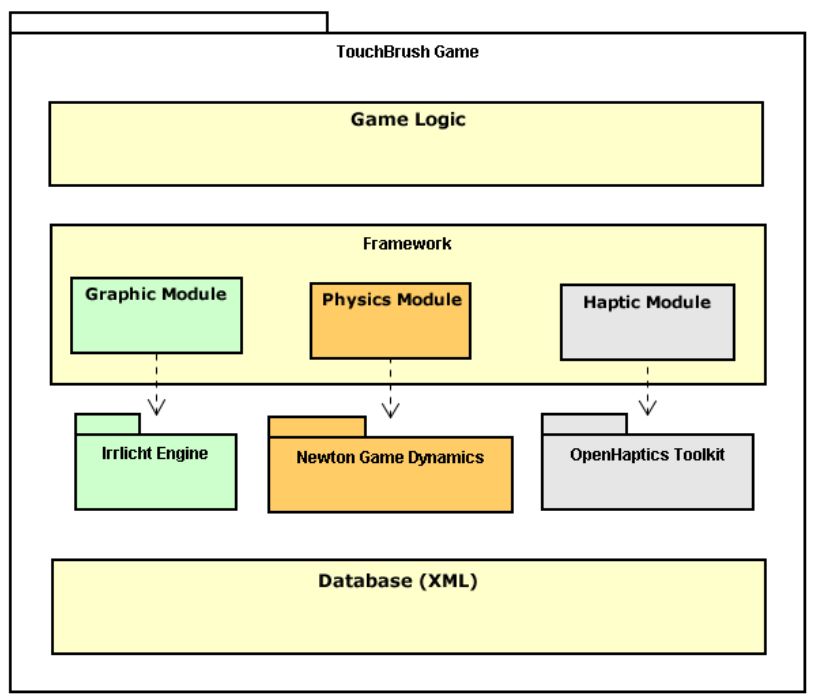

Fig. 6. Game Architecture.

A set of classes was created for the game TouchBrush. Among the main classes, can be highlighted the Game class, 
which initializes the graphics engine and features the main game loop. The class Game Manager, which carries all the information from an XML file represented by the Data Base, creates all levels and tasks and adds all objects that are part of the game scene defining their positions, rotations, lighting and material properties. The Object class defines all the variables and methods required for the interaction of objects in the scene. The Physics and PHAhantom Omni Device represent the main classes of modules Physical and Haptic. Finally, one of the major classes of the game, the Player class, represents the haptic device in the environment.

\section{A. Haptic Rendering}

As most of haptic devices, PHANToM Omni provides a single point of contact. The haptic rendering is performed by using the "proxy" method (Ruspini et al. 1997). The proxy, also known as "god-object", is an object that closely follows the position of the haptic device. In the case of this game, the proxy is represented by the Player class and has a virtual model of a tooth brush. The brush position (proxy) is limited to the outside surfaces of virtual objects in the game environment. The haptic rendering library (Open Haptic) constantly updates, at a $1000 \mathrm{~Hz}$ frequency, the position of the device in an attempt to change its position in the virtual world.

Although the real position of the haptic device can penetrate the objects, the toothbrush model is always out off the surface. When it is not touching an object, the brush will be always placed in the same position of the device (Figure 7-1). But, when in contact with an object, whether a tooth or gums, the haptic device will penetrate the surface (Figure 7-3) so that the brush will be out (Figure 7-2). The force sent to the haptic device is calculated from the penetration depth into the object in relation with the final position of the toothbrush in the surface.

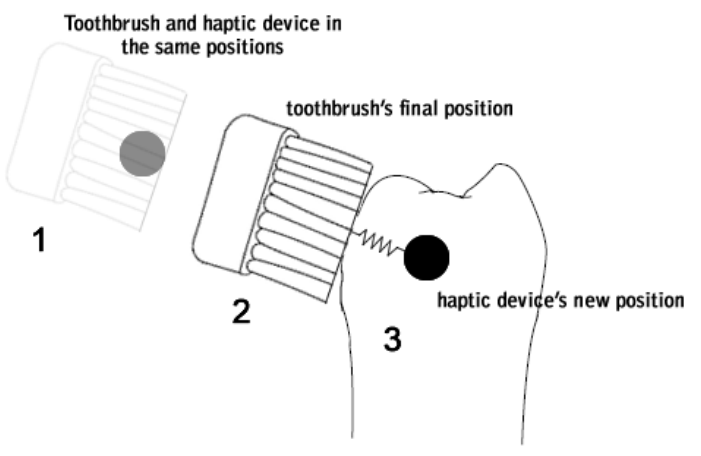

Fig. 7. Graphical representation of Haptic Rendering steps.

\section{B. Content Validation}

The last activity of the Specific Content Design (Figure 2) was the validation of the contents related to the topic of oral hygiene for adults. This step occurred with the presence of the Dentistry expert who participated in all previous project meetings during the development stages.

For the game design, the technique chosen as the base for providing learning in oral hygiene was the Bass's technique.
This technique has as main characteristic the more effective plaque removal, especially at gum level. It is the most recommended technique for most adult patients according to experts. The brushing movements description based on the oblique technique were analyzed in each of the tasks, but also, the full range of oral health tips and texts related to oral diseases caused by poor oral hygiene.

The validation was essential to confirm the importance of the pedagogical basement acquired during Requirements Analysis and Specific Content Design disciplines. It also confirmed a successful partnership with the multidisciplinary team throughout all phases of the application of the model process adopted for the construction of this game. Thus, it is important to note that the efforts of the activities of the Project Management discipline should continue throughout implementation, especially at the end, when assessing if the content transmitted to the user is correct.

\section{Results}

The TouchBrush serious game goal is to provide adults learning in the theme oral hygiene, allowing them to run manually, through the haptic device, the technique of oblique brushing adopted for this game. Thus, the user receives a set of tasks (in different levels of difficulty) and in each one there is a description of the correct movement that the user must perform. The movement description for each task is based in Table IV.

Importantly, this game does not have the function of training the user in regard to the correct handling of the toothbrush, but to inform the correct movements of a good oral hygiene by describing a technique for adults as it is defined in the literature. The same way, it aims to fix these movements in a funny way, inserting elements with realistic interaction using a haptic device and entertainment elements such as scores, challenges, and time, among others.

This serious game encompasses several types of games, and can be classified in the categories of education, simulation and skill. Educational, because seeks to provide means for producing and constructing a knowledge, in this case, inserting tasks or challenges and difficulty levels on brushing technique; Simulation, because the game simulates an everyday life situation, "teeth brushing"; And skill, because the player needs to develop motor coordination, in this case, by handling a haptic device to win the game.

The interaction in the game is through the mouse and keyboard to the out game interface, and through the haptic device and keyboard to the in game interface. The in game interface is the one available during the game and is responsible for the player data entry to the application. The out game interface, in turn, is the one that displays the main menu of the game, the description of the challenges and tasks, settings, instructions, etc. (Machado et al., 2009). With the mouse, the player can click on the buttons that appear on all screens. And with the keyboard, he can use the keys "enter" and "esc" to follow or leave the screens, besides directional arrows to rotate virtual objects when playing. 
When initially played, the TouchBrush serious game presents the player a first screen with the title of the game and a menu of options (Figure 8a). At the Options screen (Figure $8 b$ ), the player is offered the possibility to define what level of difficulty he wants to start, choosing the easy, intermediate or hard levels. Then, they can set what type of device he wants to use while running the game, choosing between the haptic device and the mouse. Finally, it can enabled or disabled the emission of sounds while running the game.

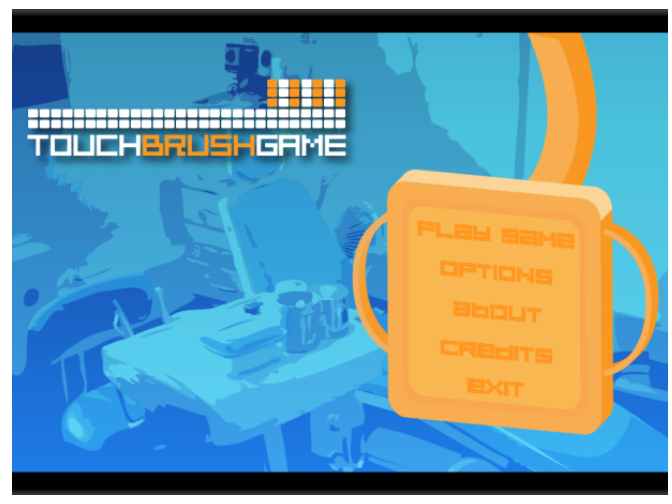

(a)

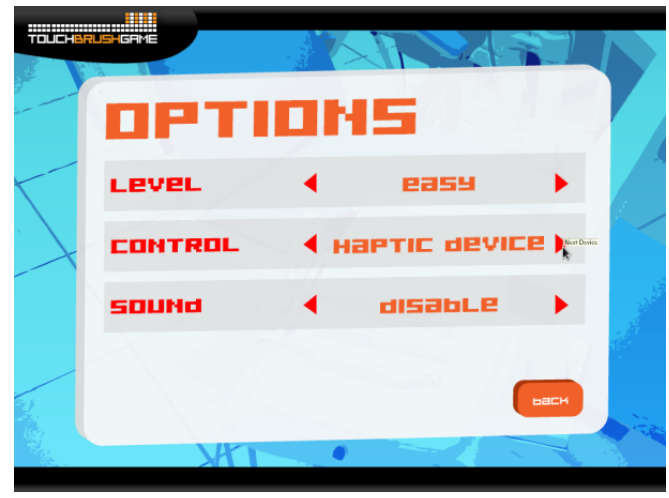

(b)

Fig. 8. Main display and options menu.

In the beginning of a task, the player is taken to a screen that refers to the difficulty level (Figure 9a). This screen displays all the information needed to accomplish the task through a picture and description (left side) and the correct movement that the player will have to run (right side) based on the oblique brushing technique. In some screens, there is a character that represents a dentist, contextualizing as all game information were mentioned by him.

Then, the user can click on the play button to start the game. It will open the three-dimensional environment with the virtual model in the center of the screen, in which the player must perform brushing according to the task goal. Figure 9b shows this environment and also all its visual components such as punctuation, brushing quality, amount of clean and dirty teeth, among others.

\section{Discussion}

The use of serious game for education is not a novelty. The Dentistry area has several applications developed to teach basic concepts of oral health. However, applications in this area that integrate haptic devices as interaction tool are mainly present in simulations and serious games for teaching advanced modalities. The suitability of devices to specific problems is something to be analyzed and the device features, its properties and price are relevant points to be considered.

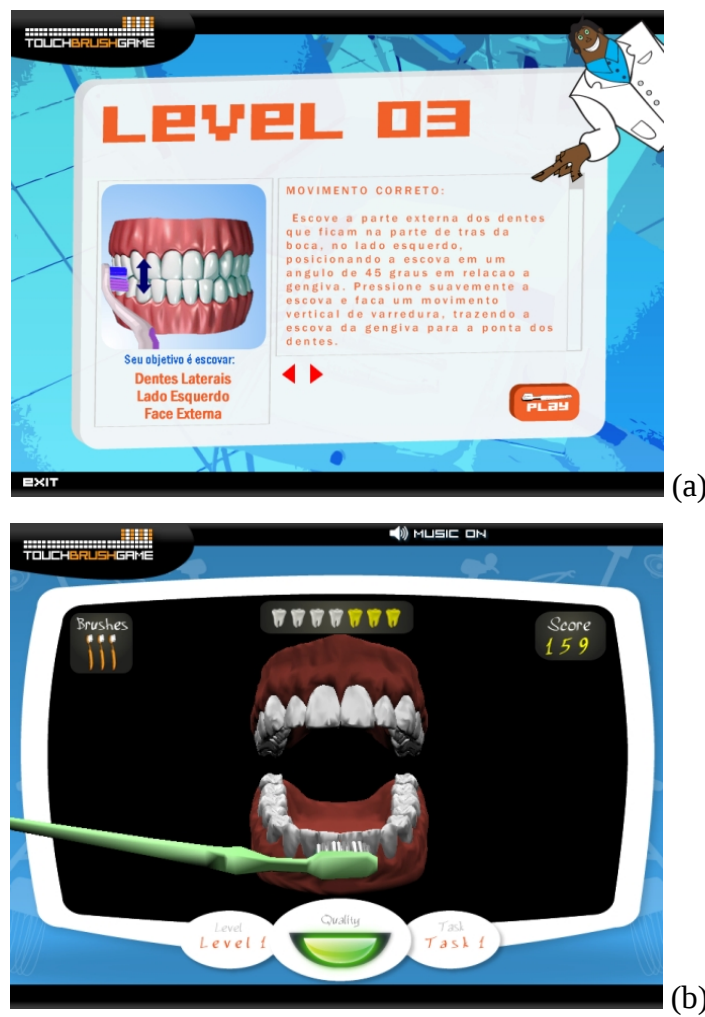

Fig. 9. Display with details of the task and game environment.

From the development of this project, the intended result of checking the use of haptic devices as a mean of interaction on a serious game to promote knowledge about oral hygiene can be considered successful. The use of a haptic device demanded the realization of previous tests with users in order to understand the best ways to integrate it to the tasks of the game. In this case, the use of a development process designed specifically to deal with serious games allowed considering the concepts and pedagogical aspects in the pre-production phase.

As regards the field of Dentistry, there are many contexts that can be operated with the use of serious games, whether directed to students or patients. The use of the SGUP made clear the importance of the involvement of a multidisciplinary team in the construction of the game. Thus, it is not enough to have a technical team that knows how to create a game, it is also necessary a set of people who can outline the scope game, 
as well as the most appropriate ways to address specific contents.

The choice of the device was preceded by an evaluation of several available devices. Even after the choice was necessary adapt the device use to the content and tasks of the game. Since the use of haptics is still something new for general public, is always important understand how users interact with them.

The third person approach brought a challenge in the perception of material properties. When using a toothbrush in yourself, the gum and the head receive forces that collaborate in the perception of the contact. Thus, the perception of forces applied by the hand with the toothbrush is combined with these other perceptions. This is not possible when performing the task in a third person and the only touch feedback is those provided by the hand with the toothbrush. Consequently, the perception of material properties is compromised with the absence of the other responses. This fact was observed in the tests when users manipulated the spheres: in a first free movement they focused in touch the spheres with the device and did not pay attention in the materials properties. When introduced to the task, several of them quickly noticed the difference of materials.

The TouchBrush game is still under evaluation, but was already possible to verify how the use of a $3 \mathrm{D}$ device can become confused when a planar view used, as in the case of using ordinary displays. Althrough $100 \%$ of users found the models with the device in the tests at the beginning of the serious game development, $20 \%$ of them had some difficulty to do it. A good solution is the use of stereoscopic view, even if non-expensive colored filter (anaglyph) glasses were used. In this case, the depth sense could improve users' recognition of distances between objects.

The size and the necessity of a reference base (for the force feedback) indicate suitability of the 3D haptic device of this project to be used in ordinary computers and not in mobile platforms, as tablets and smartphones. However, devices with 3DOF as the PHANToM Omni are still expensive and little popular for general public.

The scientific community must continue addressing the creation and development of haptic systems in serious games, as this study showed that there are few initiatives of this type of technology in this area (most applications are simulations or training systems, not serious games). The analysis guidelines, process and implementation presented, can be used as start for new opportunities of serious games creations with this order. It is thought that the combination of technologies make the understanding of information related to the tactile nature characteristics more complete, and thus, allow a constant evolution of new games with this kind of content.

\section{Conclusions}

The development of the haptic systems area opened new ways of interaction that are increasingly exploited by various knowledge areas. In health, for example, applications such as simulators for medicine training included haptic technologies in order to provide a realistic implementation of procedures and increase the level of immersion experienced by users. The use of games with specific content, such as educational or training, is increasingly expanding in various sectors of society.

It is important to highlight that in the development of a serious game, a multidisciplinary team plays a key role because it is able to evaluate and validate what is being transmitted by the game and therefore verify if the player will be able to absorb the content. In the case of TouchBrush serious game, the team was composed of professionals from the fields of Computing, Dentistry and Statistics.

Knowing the complexity involved in the development of a serious game, especially regarding aspects of inter and multidisciplinary, it is concluded that the use of development techniques are important to allow adequate approach and balance between entertainment, specific content and use of new technology. In this sense, the SGUP process model used allowed to help the teams involved throughout the serious game construction, since it set the stages, phases, disciplines and activities that helped in the composition of the team, marking what would be done at each stage of the developing process and expanding the quality level of the artifacts built.

\section{ACKNOWLEDGMENT}

This work was partially supported by the CNPq, processes 551903/2009-0 and 310561/2012-4 .

\section{REFERENCES}

[1] Andrews, S.; Mora, J.; Lang, J.; Lee, W. (2006). "HaptiCast: A Physically Based 3D Game with Haptic Feedback”, Emerging Input/Output in Games, Futureplay, Canada.

[2] Barnes T.; Encarnação L. M.; Shaw D. (2009). “Serious Games”, IEEE Computer Graphics and Applications 29(2): 18-19.

[3] Basdogan, C.; Ho, C.; Srinivasan, M.; Slater, M. (2000). "An Experimental Study on The Role of Touch in Shared Virtual Environments”, ACM Transactions on Computer-Human Interaction 7(4):443-460.

[4] Blackman, S. (2005). "Serious Games... and Less!”, Computer Graphics, 39(1):12-16. ACM, 2005.

[5] BreakAway. (2009). "Virtual Dental Implant Training (VDIT)" <http:// www.breakawaygames.com/serious-games/solutions/healthcare> (accessed August, 2009).

[6] Buchanan, J. A. (2001) "Use of Dental Simulation Technology in Dental Education.” J Dent Educ 65(11): 1225-1231.

[7] Burdea, G. (1996). Force and Touch Feedback for Virtual Reality. Wiley-Interscience.

[8] Burdea, G.; Coiffet, P. (2003) Virtual Reality Technology, $2^{\text {nd }}$ ed. WileyIEEE Press.

[9] Chang, D. (2002). "Haptics: Gaming's New Sensation”, Computer, 35(8): 84 - 86. ACM.

[10] Chang, Y., Lo, J., Huang, C., Hsu, N., Chu, H., Wang, H., Chi, P., Hsieh, Y. (2008). "Playful Toothbrush: UbiComp Technology for Teaching Tooth Brushing to Kindergarten Children”. In Proceedings of CHI 2008, pp. 363 - 372, New York, NY, USA.

[11] Chen, L.; Fujimoto, H. (2003). “A Dental Training System Using Virtual Reality”, Proc. of 2003 IEEE Int. Symp. On Computational Intelligence in Robotics and Automation, pp. 430-434.

[12] De Paolis, L., Pulimeno, M. and Aloisio, G. (2007). "The Simulation of a Billiard Game Using a Haptic Interface”, in Roberts D. J. (ed.) "Proceedings of the 11th IEEE International Symposium on Distributed Simulation and Real Time Applications", Los Alamitos, CA: IEEE Computer Society, pp. 64-67. 
[13] Demachy, T. (2003) "Extreme Game Development: Right on Time, Every Time. Gamasutra Artigo”, <www.gamasutra.com/resource_guide/ 20030714/demachy_pfv.htm> (accessed September, 2010).

[14] Faust, M.; Yong-Ho, Y. (2006). "Haptic Feedback in Pervasive Games”, Third International Workshop on Pervasive gaming applications; PerGames, Ireland.

[15] Flood, K. (2003). “Game Unified Process (GUP)”, GameDev.net Articles, <http://www.gamedev.net/reference/articles/article1940.asp> (accessed May, 2010).

[16] Guillén-Nieto, V. and Aleson-Carbonell, M. (2012) "Serious games and learning effectiveness: The case of It's a Deal!”. Computers \& Education 58(1): 435-448

[17] Johnsen K.; Raij, A.; Stevens, A.; Lind, D. S.; Lok, B. (2007). "The Validity of a Virtual Human Experience for Interpersonal Skills Education”. Proc. SIGCHI Conf. on Human Factors in Computing Systems (CHI ’07), ACM, pp. 1049-1058.

[18] Kim, L., Hwang, Y., Park, S.H., Ha, S. (2005). “Dental Training System Using Multi-modal Interface”. Computer-Aided Design \& Applications 2(5): 591-598.

[19] LeBlanc V. R., Urbankova A., Hadavi F., Lichtenthal R. M. (2003). “A Preliminary Study in Using Virtual Reality to Train Dental Students”. Journal on Dental Education 68(3): 378-383.

[20] Lindhe,,J., Karring, T., Lang, N. (2003) Clinical Periodotology and Implant Dentistry, 41th edition. Blackwell Munksgaard.

[21] Liu, G., Zhang, Y., and Townsend, W. T. (2008). "Force Modelling for Tooth Preparation in Dental Training System”. Virtual Reality, 12(3): 125-136.

[22] Luciano, C. J. (2006) "Haptics-based Virtual Reality Periodontal Training Simulator". Master Dissertation, Graduate College of the University of Illinois.

[23] Machado, L.S., Moraes, R.M., Souza, D.F.L, Souza, L.C., Cunha, I.L.L. (2009). "A Framework for Development of Virtual Reality-Based Training Simulators". Studies in Health Technology and Informatics 142: 174-176. IOSPress.
[24] Machado, L.S., Moraes, R.M., Nunes, F.L.S., Costa, R.M.M (2011) "Serious Games Based on Virtual Reality in Medical Education". Revista Brasileira de Educação Médica 35(2):254-262.

[25] Marsh, T. (2011) "Serious games continuum: Between games for purpose and experiential environments for purpose”. Entertainment Computing, 2(2): 61-68. Elsevier.

[26] Moraes, R.M.; Machado, L.S.; Marques, F.L.S.N.; Costa, R.M.E.M (2012) Serious Games and Virtual Reality for Education, Training and Health. In: Maria Manuela Cruz-Cunha (Ed.). (Org.). Handbook of Research on Serious Games as Educational, Business and Research Tools. : IGI Global, p. 315-336.

[27] Morais, A. M.; Rodriges, H. F.; Machado, L. S.; Valença, A. M. G. (2010) "Planning Serious Games: Adapting Approches for Development”. Lecture Notes in Computer Science 6249: 385-394. Springer.

[28] Morris, D., Neel, J., and Salisbury, K. (2004). "Haptic Battle Pong: High-Degree-of-Freedom Haptics in a Multiplayer Gaming Environment”. Experimental Gameplay Workshop, GDC.

[29] Ranking, J. R.; Vargas, S. S. (2008). “A Review of Serious Games and Other Game Categories for Education”, SimTect 2008, Melbourne, Australia, pp. 305-311.

[30] Rodrigues, H (2010). "Definição e Aplicação de um Modelo de Processo para o Desenvolvimento de um Serious Game na Área de Saúde". Proc. Workshop on Medical Informatics. Belo Horizonte - Brazil. p. 1532 1541.

[31] Ruspini, D. C.; Kolarov, K.; Khatib, O. (1997). "The Haptic Display of Complex Graphical Environments”. Proc. of ACM SIGGRAPH.

[32] Schell, J. (2008) The Art of Game Design: A book of lenses. CRC Press.

[33] VRDTS. (2001). "Virtual Reality Dental Training System (VRDTS)" $<$ http://home.novint.com/products/medical_dental.php> (accessed August, 2009).

[34] Zyda, M. (2005). "From Visual Simulation to Virtual Reality to Games”, In: IEEE Computer Society (9): 2532. 